\title{
Ionization and NO production in the polar mesosphere during high-speed solar wind streams: model validation and comparison with NO enhancements observed by Odin-SMR
}

\author{
S. Kirkwood ${ }^{1}$, A. Osepian ${ }^{2}$, E. Belova ${ }^{1}$, J. Urban ${ }^{3, \dagger}$, K. Pérot ${ }^{3}$, and A. K. Sinha ${ }^{4}$ \\ ${ }^{1}$ Polar Atmospheric Research, Swedish Institute of Space Physics, P.O. Box 812, 98128 Kiruna, Sweden \\ ${ }^{2}$ Polar Geophysical Institute, Halturina 15, 183023 Murmansk, Russia \\ ${ }^{3}$ Department of Radio and Space Science, Chalmers University of Technology, Hörsalsvägen 11, \\ 41296 Gothenburg, Sweden \\ ${ }^{4}$ Indian Institute of Geomagnetism, 410218 Navi Mumbai, India \\ $\dagger$ deceased
}

Correspondence to: S. Kirkwood (sheila.kirkwood@irf.se)

Received: 27 October 2014 - Revised: 21 April 2015 - Accepted: 23 April 2015 - Published: 26 May 2015

\begin{abstract}
Precipitation of high-energy electrons (EEP) into the polar middle atmosphere is a potential source of significant production of odd nitrogen, which may play a role in stratospheric ozone destruction and in perturbing large-scale atmospheric circulation patterns. High-speed streams of solar wind (HSS) are a major source of energization and precipitation of electrons from the Earth's radiation belts, but it remains to be determined whether these electrons make a significant contribution to the odd-nitrogen budget in the middle atmosphere when compared to production by solar protons or by lower-energy (auroral) electrons at higher altitudes, with subsequent downward transport. Satellite observations of EEP are available, but their accuracy is not well established. Studies of the ionization of the atmosphere in response to EEP, in terms of cosmic-noise absorption (CNA), have indicated an unexplained seasonal variation in HSS-related effects and have suggested possible order-ofmagnitude underestimates of the EEP fluxes by the satellite observations in some circumstances. Here we use a model of ionization by EEP coupled with an ion chemistry model to show that published average EEP fluxes, during HSS events, from satellite measurements (Meredith et al., 2011), are fully consistent with the published average CNA response (Kavanagh et al., 2012). The seasonal variation of CNA response can be explained by ion chemistry with no need for any seasonal variation in EEP. Average EEP fluxes are used to estimate production rate profiles of nitric oxide between 60 and
\end{abstract}

$100 \mathrm{~km}$ heights over Antarctica for a series of unusually well separated HSS events in austral winter 2010. These are compared to observations of changes in nitric oxide during the events, made by the sub-millimetre microwave radiometer on the Odin spacecraft. The observations show strong increases of nitric oxide amounts between 75 and $90 \mathrm{~km}$ heights, at all latitudes poleward of $60^{\circ} \mathrm{S}$, about 10 days after the arrival of the HSS. These are of the same order of magnitude but generally larger than would be expected from direct production by HSS-associated EEP, indicating that downward transport likely contributes in addition to direct production.

Keywords. Atmospheric composition and structure (middle atmosphere - composition and chemistry)

\section{Introduction}

Production of nitric oxide (NO) in the polar upper atmosphere by energetic particle precipitation is considered to be an important source of NO in the polar winter stratosphere, where it contributes to ozone destruction and, as a consequence, may affect radiative heating, modify circulation patterns and possibly even affect climate (for a recent review see Sinnhuber et al., 2012). Most odd nitrogen is produced in the thermosphere, above $100 \mathrm{~km}$ altitude, by electrons with energies up to a few $\mathrm{keV}$, which are accelerated in the Earth's magnetosphere and precipitated in the northern 
and southern auroral zones. From the thermosphere, NO can be transported downward, particularly in polar winter, when its lifetime is long (due to a lack of sunlight) and the residual circulation is downward. There is also the possibility of direct production of NO below $100 \mathrm{~km}$ altitude by solar protons with $\mathrm{MeV}$ energies, by solar X-rays and by energetic electrons which are energized and precipitated from within the Earth's magnetosphere with energies in excess of $10 \mathrm{keV}$. Solar proton events are the result of coronal-mass-ejection (CME) events on the Sun. They are rare, typically affecting about 100 days in any 10-year solar cycle, but the proton fluxes can be high. Direct changes in middle-atmosphere composition down to $40-50 \mathrm{~km}$ heights have been demonstrated during solar proton events (see e.g. Jackman et al., 2014; Sinnhuber et al., 2014, and references therein). Since solar proton events occur primarily close to the maximum of the solar sunspot cycle, it has been suggested that these could be a source of climate forcing in phase with the solar cycle.

It has been known since the beginning of the satellite age that there are large numbers of high-energy particles trapped in the radiation belts in the Earth's magnetosphere. It is also well known that their pitch angles can be scattered into the loss cone so that they are precipitated into the atmosphere when the magnetosphere is disturbed by changing conditions in the solar wind (e.g. Lyons et al., 1972). It has long been suspected that energetic electrons precipitated during geomagnetic disturbances could be a source of electron density and NO enhancements observed (by sounding rockets) not only at high latitudes but, with a few days' delay, also at mid-latitudes (e.g. Dickinson and Benett, 1978; Torkar et al., 1980). The availability of direct observations of the solar wind in recent decades has led to an understanding that the arrival of high-speed solar wind streams (HSS) at Earth is a major source of energization, pitch-angle scattering and precipitation of high-energy electrons into the atmosphere (see review by Baker and $\mathrm{Li}, 2003$ ). Statistical studies of energetic electrons using instruments on the Polar Orbiting Environmental Satellites (POES) have shown that there are large increases in the fluxes of both trapped and precipitating electrons associated with HSS, affecting electron energies from $30 \mathrm{keV}$ to some $\mathrm{MeV}$ (the limits of the observations) (Meredith et al., 2011). These can be expected to reach altitudes between 50 and $90 \mathrm{~km}$ in geomagnetic latitude bands between about $55-70^{\circ} \mathrm{N}$ or S. Further, since the solar coronal holes which cause HSS are more prevalent around the declining phase of the solar sunspot cycle, and HSS occur much more frequently than solar proton events, it has been suggested that the result may be climate forcing which is not exactly in phase with the solar cycle. A chemistry-climate simulation by Rozanov et al. (2005) suggested that energetic electron precipitation could have as much or more of an effect on climate than the changes in solar UV fluxes between solar maximum and solar minimum.

The accuracy of POES measurements of energetic electron precipitation (EEP) for low fluxes has been questioned by Rodger et al. (2013), who found a mismatch between measured fluxes and their expected effect in the middle atmosphere. Rodger et al. (2013) used calculations of electron density profiles based on measured EEP fluxes, then calculated the expected cosmic-noise absorption (CNA) corresponding to the electron density profiles and compared with CNA observations. They found that measured CNA was an order of magnitude higher than expected on the basis of the EEP measurements when EEP fluxes (for energies $>30 \mathrm{keV}$ ) were reported as $<10^{6} \mathrm{~cm}^{-2} \mathrm{~s}^{-1} \mathrm{sr}^{-1}$. This would imply that EEP fluxes and NO production rates are underestimated by 2 orders of magnitude when based on the POES measurements. Since statistical average HSS-related EEP fluxes (Meredith et al., 2011) are below $10^{6} \mathrm{~cm}^{-2} \mathrm{~s}^{-1} \mathrm{sr}^{-1}$, it is then not clear whether they represent true conditions or are underestimated by a large factor.

The EEP-CNA comparison made by Rodger et al. (2013) was not specifically concerned with HSS-related disturbances. It was also based only on short intervals of night-time observations at a single CNA measurement site in the auroral zone, where the effects of auroral electron precipitation (energies $<10 \mathrm{keV}$ ) could potentially have affected the results. In a separate study, Kavanagh et al. (2012) compiled a statistical view of the CNA response specifically to HSS-related disturbances. The latter uses a much larger number of measurement sites for CNA and includes all times of the day and all seasons. Kavanagh et al. (2012) found a strong response of CNA to HSS, with systematic daily and seasonal variations. Although they were qualitatively able to explain the daily variation by the expected daily variation in EEP fluxes (e.g. Meredith et al., 2011), they could not find any evidence of a seasonal variation in EEP and were unable to find an explanation for the seasonal variation in CNA response. They did not attempt to make a quantitative comparison between the CNA response and EEP fluxes.

In the current paper we use the statistical averages of HSSrelated EEP fluxes based on POES measurements (Meredith et al., 2011) to calculate ionospheric electron density profiles and associated CNA and make a quantitative comparison with the observed statistical response in CNA (Kavanagh et al., 2012). We further compare NO production rates, calculated on the basis of statistical EEP fluxes, to direct measurements of NO increases in the Antarctic winter middle atmosphere associated with HSS events.

\section{Ion and NO production rate model}

The statistical characteristics of both precipitating and trapped energetic electron fluxes associated with HSS have been comprehensively documented by Meredith et al. (2011) in terms of integral fluxes for energies $>30,>100$ and $>300 \mathrm{keV}$. In order to calculate ion (and hence NO) production rate profiles, differential flux-energy spectra of the precipitating electrons are needed. Kirkwood et al. (2001) 
used a pitch-angle scattering model for the kind of conditions expected during HSS, together with comparisons between satellite measurements of trapped fluxes, incoherentscatter radar measurements of the resulting electron density profiles in the atmosphere, and observations of CNA, to show that an exponential form for the differential flux was consistent with the measurements. However, the latter study covered only the energy range $30-200 \mathrm{keV}$. A simple exponential form for the differential flux-energy spectrum does not give a good enough fit to the integral fluxes in Meredith et al. (2011), which include higher energies. Neither does a power law, as proposed by Rodger et al. (e.g. 2013). The exponential form gives too high fluxes between 100 and $300 \mathrm{keV}$, and the power law gives too low fluxes, compared to the 30-100 and $>300 \mathrm{keV}$ intervals. Therefore here we use an exponential form for energies below $100 \mathrm{keV}$, with a power-law tail covering the higher energies. This allows a close fit to the integral fluxes, within the precision with which they can be read from the figures in Meredith et al. (2011). The details of the fitted flux-energy spectra for the day following HSS onset (for $L=5$, but there is no significant difference for $L=6$ ) are shown in Table 1, where three alternatives are given, corresponding to the upper quartile (UQ-HSS), mean (mean-HSS) and lower quartile (LQ-HSS) levels of the integral fluxes. The statistical study by Meredith et al. (2011) does not provide any direct information on fluxes for energies below $30 \mathrm{keV}$. Electrons with these relatively low energies do not penetrate below $90 \mathrm{~km}$ altitude, so this part of the distribution is not important for the ionization in the mesosphere. However, any NO produced will have a much longer lifetime than the ionization and might be redistributed by vertical transport, becoming important in polar winter (when the large-scale circulation has a downward component) for NO concentrations even at much lower heights. Thus we also illustrate the effect of including a lower-energy source, a typical auroral flux (Kirkwood and Eliasson, 1990), also listed in Table 1 (we cut off this flux at $30 \mathrm{keV}$, so there is no contribution to the integral flux at $>30 \mathrm{keV}$ ). Finally we introduce a variation over magnetic local time in the form of a smoothed fit to the variation documented in Meredith et al. (2011) for $>30 \mathrm{keV}$ fluxes. This is illustrated in the top panel of Fig. 1 . We apply the same factor to all fluxes, so that the same $e$ folding energy for the exponential and power-law coefficient for the tail is used at all magnetic local times (MLTs). This may not be completely accurate, but the uncertainties in this approximation will be less than the very large differences between mean, upper and lower quartile fluxes.

Ionization rate and ion/electron density profiles are calculated using the model documented in Kirkwood and Osepian (1995). This uses ionization rate calculations based on the methods of Rees (1963). To give us the possibility to validate the model by comparison with other observations, we also need to include other sources of ionization and we need to compute electron density profiles from the ionization rates. This is achieved using the positive-ion chemistry
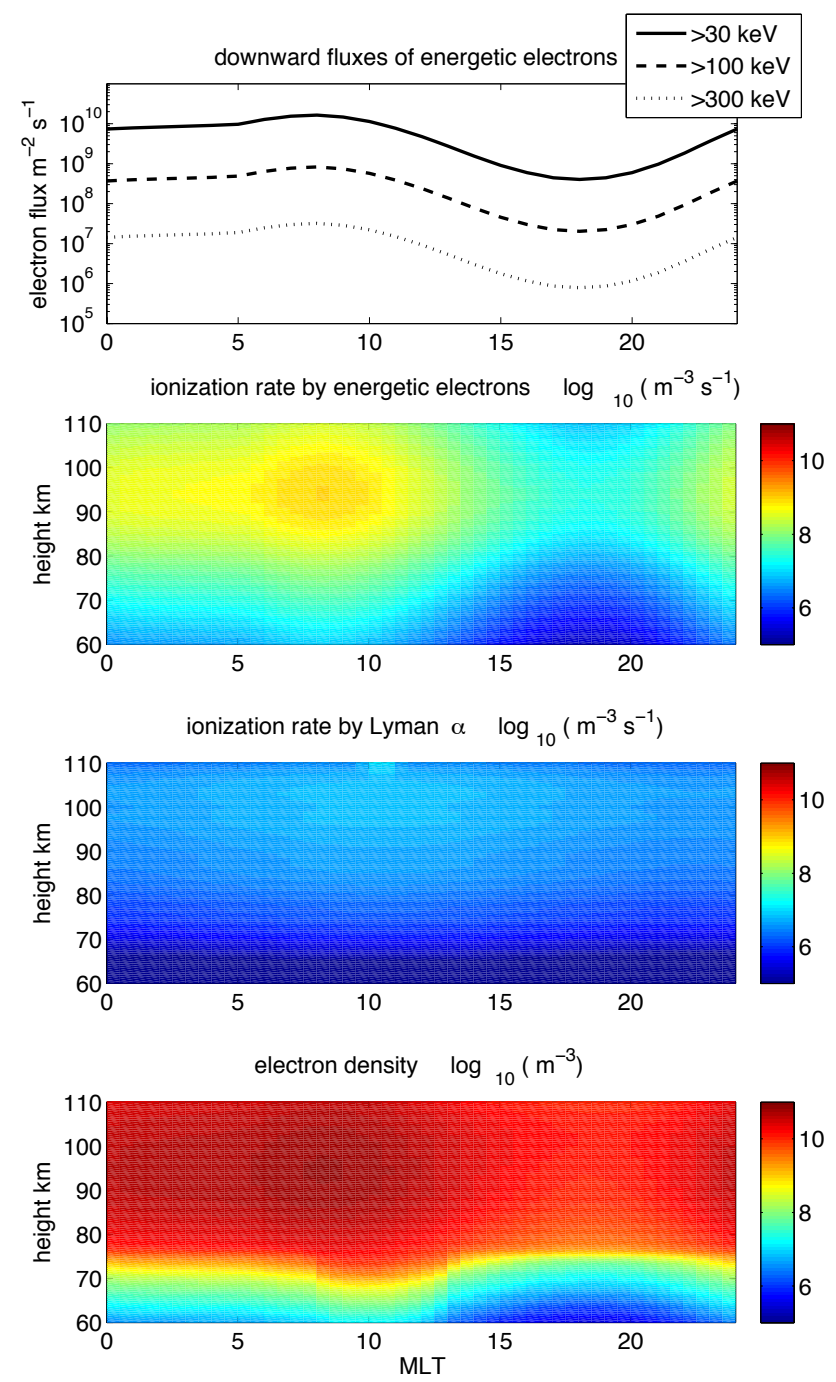

Figure 1. Example model calculations for winter solstice, for the location of Maitri Station, Antarctica, at geomagnetic latitude $63^{\circ} \mathrm{S}$, geographic latitude $71^{\circ} \mathrm{S}$. Top panel: input fluxes of energetic electrons, corresponding to the UQ-HSS model in Table 1. Second panel: ionization rate by energetic electrons. Third panel: ionization rate of $\mathrm{NO}$ by solar Lyman $\alpha$ radiation, including nightglow. Fourth panel: resulting electron density. Timescale is in magnetic local time (MLT). Local solar noon is at 10:04 MLT.

model of Smirnova et al. (1988) (with four representative ions: $\mathrm{O}_{2}^{+}, \mathrm{NO}^{+}$, a simple cluster ion and a complex cluster ion) and the negative-ion model of Torkar and Friedrich (1983) (two representative ions: $\mathrm{O}_{2}^{-}, \mathrm{X}^{-}$). The underlying neutral atmosphere model is MSIS00E (http://ccmc.gsfc. nasa.gov/modelweb/atmos/msise.html; Hedin, 1991). There are two important updates to the model as compared to the description in Kirkwood and Osepian (1995) - a correction for energetic particle albedo (Sergienko and Ivanov, 1993) which reduces ionization rates by a factor of 0.62 and the inclusion of UV ionization sources including nightglow (fol- 
Table 1. Mean daily downward differential flux models used to calculate ionization rate profiles. Fluxes at energies $E>30 \mathrm{keV}$ are power-law fits to precipitating fluxes during the first day following the arrival of high-speed solar wind streams according to Meredith et al. (2011). Fits to the lower quartile (HSS-LQ), mean (HSS-mean) and upper quartile (HSS-UQ) integral fluxes are shown (note that mean fluxes are higher than UQ). "Aurora" is a representative auroral spectrum (Kirkwood and Eliasson, 1990). Corresponding integral fluxes for $E>30,100$ and $300 \mathrm{keV}$ are shown in the last three columns for comparison with Meredith et al., 2011.

\begin{tabular}{llllll}
\hline & $\begin{array}{l}\text { Differential flux } \\
<100 \mathrm{keV} \\
\mathrm{cm}^{-2} \mathrm{~s}^{-1}\end{array}$ & $\begin{array}{l}\text { Differential flux } \\
100 \mathrm{keV} \\
\mathrm{cm}^{-2} \mathrm{~s}^{-1}\end{array}$ & $\begin{array}{l}\text { Integral flux } \\
>30 \mathrm{keV} \\
\mathrm{cm}^{-2} \mathrm{~s}^{-1} \mathrm{sr}^{-1}\end{array}$ & $\begin{array}{l}\text { Integral flux } \\
>100 \mathrm{keV} \\
\mathrm{cm}^{-2} \mathrm{~s}^{-1} \mathrm{sr}^{-1}\end{array}$ & $\begin{array}{l}\text { Integral flux } \\
>300 \mathrm{keV} \\
\mathrm{cm}^{-2} \mathrm{~s}^{-1} \mathrm{sr}^{-1}\end{array}$ \\
\hline Mean-HSS & $\begin{array}{l}5.34 \times 10^{4} \exp (-E / 39.4) \\
\text { UQ-HSS }\end{array} 1.39 \times 10^{5} \exp (-E / 19.90)$ & $\begin{array}{l}2.18 \times 10^{1} 2 E^{-4.36} \\
6.89 \times 10^{1} 0 E^{-3.70}\end{array}$ & $3.0 \times 10^{5}$ & $4.0 \times 10^{4}$ & $9.9 \times 10^{2}$ \\
LQ-HSS & $1.53 \times 10^{3} \exp (-E / 21.9)$ & $5.47 \times 10^{5} E^{-2.27}$ & $3.0 \times 10^{3}$ & $1.0 \times 10^{4}$ & $3.9 \times 10^{2}$ \\
Aurora & $3.00 \times 10^{8} \exp (-E / 2)$ & 0 & 0 & $3.8 \times 10^{2}$ & $7.8 \times 10^{1}$ \\
\hline
\end{tabular}

lowing Kashirin, 1986). At the heights of interest, the main contribution is ionization of NO by Lyman $\alpha$. The ionization and ion-chemistry calculations require appropriate minorconstituent models for $\mathrm{NO}$ and $\mathrm{H}_{2} \mathrm{O}$, respectively. For $\mathrm{H}_{2} \mathrm{O}$ we have made an analytical approximation to the climatologies reported by Hartogh et al. (2010) (from a decade of year-round measurements from Andenes, northern Norway) and by Rong et al. (2010) (polar summer mesosphere in both hemispheres observed by the SOFIE instrument on the AIM satellite). This is illustrated in the right-hand panel of Fig. 2.

Our model of NO is based on measurements by the SubMillimeter Radiometer (SMR) instrument on the Odin satellite (Murtagh et al., 2002). Trace-gas measurements, including NO, have been made by Odin-SMR since October 2003 (for a description of the measurement technique see Urban et al., 2007). Until May 2007, the relevant height range was covered for only about 1 day per month, but since then the coverage has increased to about 4 days per month. Odin travels in a quasi-polar Sun-synchronous orbit which nominally crosses the Equator at 06:00 and 18:00 LT (in practice this has varied between 06:00 and 07:00 LT and 18:00 and 19:00 LT between 2003 and 2014). There are about 15 orbits per day and measurements are made by limb scanning on both ascending and descending nodes. Estimates are provided at $1 \mathrm{~km}$ height intervals but the true height resolution in the mesosphere is about $7 \mathrm{~km}$. Individual profile measurements show high variability, and averages have to be used to give geophysically reliable results (Sheese et al., 2013). For this study, daily zonal averages have been computed for $5^{\circ}$ bins of geomagnetic latitude (as in Kirkwood et al., 2013), each representing an average over, typically, about 40 different measurements. Since HSS events can be expected to lead to changes in the NO number density, we develop an empirical model which accounts for this, using solar wind speed observations from the Wind spacecraft (http://omniweb.gsfc.nasa.gov/). Measurement days corresponding to three different solar wind conditions are identified - pre-HSS, where solar wind speed is below $500 \mathrm{~km} \mathrm{~s}^{-1}$ for the entire day but increases to above
$500 \mathrm{~km} \mathrm{~s}^{-1}$ sometime the following day; onset-HSS, where solar wind speed was below $500 \mathrm{~km} \mathrm{~s}^{-1}$ for the entire previous day but increases to above $500 \mathrm{~km} \mathrm{~s}^{-1}$ sometime during the current day; and post-HSS, where solar wind speed is above $500 \mathrm{~km} \mathrm{~s}^{-1}$ for the entire day and has been above $500 \mathrm{~km} \mathrm{~s}^{-1}$ for the preceding $24 \mathrm{~h}$. We exclude any observations made within 20 days after a solar proton event (defined as proton flux $>10 \mathrm{~cm}^{-2} \mathrm{~s}^{-1} \mathrm{sr}^{-1}$ at $10 \mathrm{MeV}$ ) or before 2007 . The number of suitable observations from Odin is small. Out of altogether 337 observation days since 2007, 24 can be identified as pre-HSS, 48 as onset-HSS and 20 as post-HSS. The resulting NO densities for the geomagnetic latitude band $60-65^{\circ} \mathrm{S}$ for summer (November-December-January), autumn (February-March-April), winter (May-June-July) and spring (August-September-October) are shown in the lefthand panel of Fig. 2. The number of observation days in each category and each season is small - for summer there are 6, 8 and 3 days in pre-, onset- and post-HSS conditions, respectively; in autumn there are 7,13 and 5 days; in winter there are 7, 16 and 8 days; and in spring there are 4,11 and 4 days. Despite the small numbers, the averages show clearly the increased background NO densities in winter, and a strong response to HSS, at all heights between 70 and $100 \mathrm{~km}$, in that season. In the first instance, these profiles will be used to estimate whether the increase in NO due to HSS can give a significant signature in CNA. In this context, we note that comparison with four other satellite instruments has shown a possible low bias for Odin-SMR NO measurements, below $100 \mathrm{~km}$ altitude, by about $10 \%$ compared to Odin-OSIRIS, and a high bias by up to $40 \%$ compared to SCIAMACHY, MIPAS and ACE-FTS (Sheese et al., 2013; Bender et al., 2014).

Example results of the modelled daily variation of ionization rate and electron density for the UQ-HSS electron flux spectrum in Table 1, for winter solstice, at an Antarctic location at $L=5.0$ (Maitri Station, geographic coordinates $70.77^{\circ} \mathrm{S} 11.73^{\circ} \mathrm{E}$ ), are shown in Fig. 1. The variation of ionization rate over the day is dominated by the prescribed variation of the precipitating electron flux. The variation of 

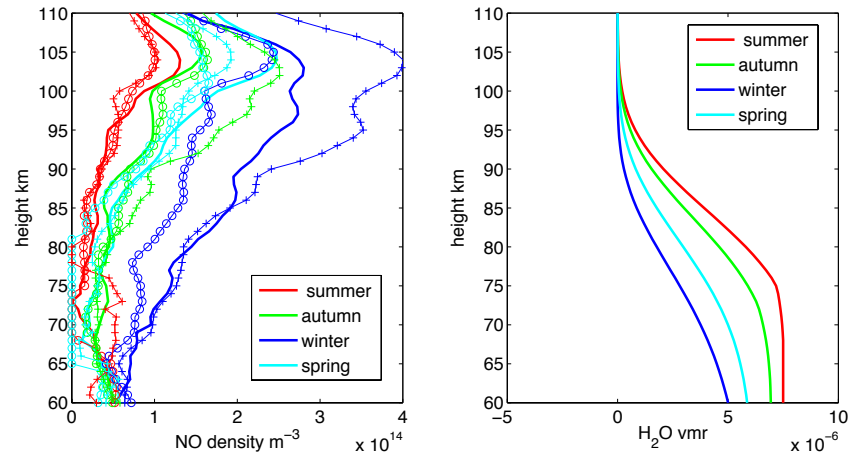

Figure 2. Model profiles of $\mathrm{NO}$ number density and $\mathrm{H}_{2} \mathrm{O}$ volume mixing ratio input into the ionization rate/ion-chemistry model. NO profiles are divided according to their relation to the arrival of highspeed solar wind streams: solid lines correspond to days including HSS arrival (onset-HSS), circles for days immediately prior to arrival (pre-HSS), crosses at least 1 day after arrival (post-HSS). See text for further details.

the electron density is further strongly affected by ion chemistry. At night, electron attachment leads to a build-up of negative ions and a strong reduction in electron density. Increased UV radiation and increased atomic oxygen density during daytime remove the electrons from the negative ions and the electron density increases (see e.g. Osepian et al., 2009b). Together, the daily variations in precipitating electron flux and ion chemistry lead to a morning maximum in the electron density. Figure 3 shows mean (over all MLTs) profiles of ionization rate and electron density corresponding to upper quartile (UQ), mean and lower quartile (LQ) HSS electron flux spectra, and onset-HSS model for NO, calculated for each month of the year (on the 23rd of each month, and then averaged for the 3 months of each season). Here it can be seen that seasonal variations in ionization rate (due to changes in atmospheric scale height following seasonal changes in temperature) are fairly small (up to a factor of 4), while the seasonal changes in electron density are greater (up to an order of magnitude). This is due to ion chemistry. For example, around $80 \mathrm{~km}$ height, the ionization rate is essentially the same in summer and winter, but electron densities are about 3 times lower in summer as a result of increased water vapour together with lower temperature, which leads to the formation of positive cluster ions which recombine with electrons more rapidly than molecular ions do. Around $60 \mathrm{~km}$ height, ionization rates in spring, autumn and summer are 2-10 times less than in winter, but electron densities are 2-5 times higher. This is due to a lack of sunlight leading to more persistent negative ion formation in winter (see e.g. Barabash et al., 2014). (It can be noted that this seasonal effect is also found in the IMAZ empirical model of the auroral-zone lower ionosphere (McKinnel and Friedrich, 2007). Although not strictly comparable, since IMAZ provides electron density as a function of CNA rather than as a function of incident electron flux, IMAZ does show that, in disturbed conditions (CNA at 27.6 MHz 0.8-2.0 dB), electron densities at $80 \mathrm{~km}$ are on average a few times higher in winter than in summer).

Computation of ionization rate profiles, and the ionchemistry modelling which is needed to calculate electron density profiles and CNA, requires complex software, with the possibility of coding errors. Therefore, for the present study, results have been carefully compared to the independently coded model described in (Osepian et al., 2008, 2009a) and Barabash et al. (2012) (which uses the same Dregion ionization sources, the same positive-ion model and a more complex negative-ion model with four ions: $\mathrm{O}^{-}$, $\mathrm{O}_{2}^{-}, \mathrm{CO}_{3}^{-}, \mathrm{NO}_{3}^{-}$), and no significant differences have been found in the calculated electron density profiles. These models have been extensively tested in various different conditions (auroral electron precipitation, solar proton events, quiet conditions) with ionization sources according to satellite measurements and electron-density measurements by sounding rockets, by partial-reflection radar and by the EISCAT incoherent-scatter radar (e.g. Kirkwood and Eliasson, 1990; Kirkwood et al., 2002; Osepian et al., 2009a, b). These models use simplified ion-chemistry and prescribed traceconstituent models to allow computational efficiency in calculating electron density profiles, as well as their dependence on trace constituents, which can be readily compared with observations. More complex ion-chemistry models such as the Sodankyla or University of Bremen models (e.g. Verronen et al., 2002; Nieder et al., 2014) use large numbers of individual ion species (up to 55 positive ions, 49 negative ions) with the aim of calculating both electron and individual ion densities and production rates of neutral trace constituents. As demonstrated by the comparisons cited above, this level of complexity is not needed to estimate electron density. Our model does not provide a direct calculation of the production of NO. Recent work using the University of Bremen model (Nieder et al., 2014) has shown that $\mathrm{NO}_{x}$ production rates should be about 1.25 times the ion production rate below $80 \mathrm{~km}$, increasing to about 1.7 times as height increases up to $110 \mathrm{~km}$, with the ratio of $\mathrm{NO} / \mathrm{NO}_{x}$ about 0.55 below $110 \mathrm{~km}$. However, the partitioning depends on conditions so here we estimate an "upper limit" NO production rate from the total ionization rate by multiplying by a factor of 1.25 , while noting that this may still be an underestimate by up to $35 \%$ between 80 and $110 \mathrm{~km}$.

\section{HSS model validation}

The statistical study of observed cosmic-noise absorption in relation to HSS by Kavanagh et al. (2012) provides an excellent validation of our model results. Figure 4 shows the MLT variation in cosmic-noise absorption (at $38 \mathrm{MHz}$ ) which would result from our modelled electron density profiles. To calculate these, we have first calculated absorption 

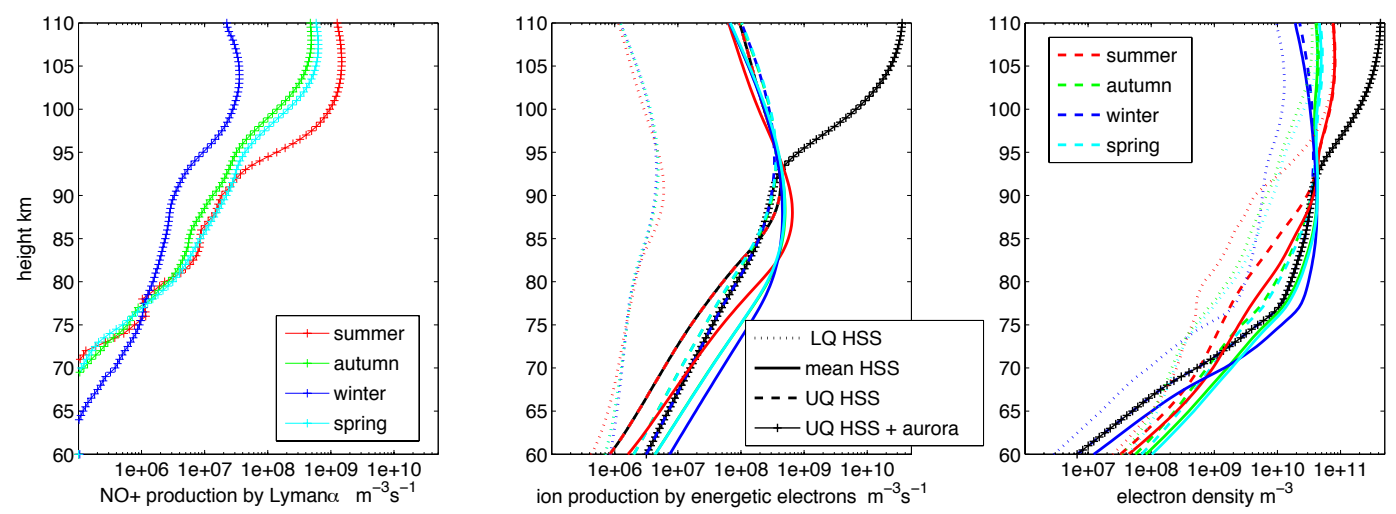

Figure 3. Seasonal averages of model calculations, for the location of Maitri Station, Antarctica. Left panel: daily average ionization rate of NO by solar Lyman $\alpha$ radiation, including nightglow. Middle panel: daily average ionization rate by energetic electrons. Right panel: resulting daily average electron density. Solid lines in the middle and right-hand panels are for mean-HSS fluxes, dotted lines are for LQ-HSS and dashed lines are for UQ-HSS.
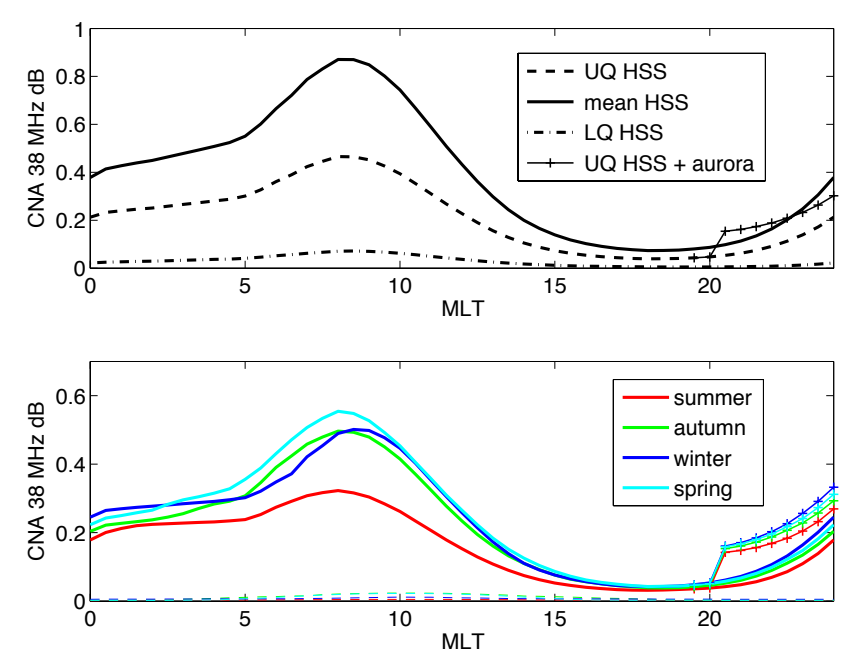

Figure 4. Averages of model calculations of cosmic-noise absorption at $38 \mathrm{MHz}$, for the location of Maitri Station, Antarctica. Top panel: annual averages for different EEP models - solid line for mean-HSS fluxes, dash-dot line for LQ-HSS and dashed line for UQ-HSS, with the addition of "aurora" fluxes to the UQ-HSS model in the $4 \mathrm{~h}$ before magnetic midnight (solid lines with + , visible only close to the right-hand edge of the plot). Lower panel: seasonal averages for UQ-HSS fluxes (plain solid lines), with the addition of "aurora" fluxes in the $4 \mathrm{~h}$ before magnetic midnight (solid lines with + ) and for the increase in absorption due to the HSS-associated NO increase, without any energetic electron precipitation (dashed lines).

for electron density profiles with pre-HSS values of NO and no electron precipitation and subtracted those absorption values from the results when electron precipitation and high NO densities (onset-HSS) are present. The upper panel shows the average (over all 12 months) for UQ-, mean- and LQHSS electron flux spectra, the lower panel shows averages for each season, for mean HSS fluxes. In the lower panel, for completeness, we also show how much CNA would result from the increase in NO corresponding to the "post-HSS" profile in Fig. 2, without any energetic electron precipitation (dashed lines). It can be seen that the latter is very small. The energetic electron precipitation is by far the dominant contribution to the CNA. We also show the effect of adding our "aurora" precipitation in the $4 \mathrm{~h}$ preceding magnetic midnight (solid lines with crosses). There is a clear contribution to CNA, by about $0.1 \mathrm{~dB}$, even though these electrons do not cause any ionization below $90 \mathrm{~km}$ altitude.

Comparing the upper panel of Fig. 4 with the first day after HSS onset in Fig. 6 of Kavanagh et al. (2012), we find generally good agreement. In our case, the annual averages for UQ-HSS and LQ-HSS models peak in the late morning hours at about 0.47 and $0.07 \mathrm{~dB}$, respectively. Corresponding observational results in Kavanagh et al. (2012) peak in the late morning hours at about 0.65 and $0.1 \mathrm{~dB}$. (We cannot compare our mean-HSS model with Kavanagh et al. (2012) since only median rather than mean values are included in the latter study.) The lower panel of Fig. 4 can be compared with Fig. 8 of Kavanagh et al. (2012). In both our model and in the observations, maximum daytime CNA is higher during the spring equinox than during winter, and the summer shows the lowest CNA values of all seasons. Note that there is absolutely no seasonal change in the spectrum of particle precipitation we have assumed - the seasonal differences in CNA are simply a result of the seasonal changes in ion chemistry. There is a slight difference between our model results and the observations in that our model predicts lower absorption in autumn than in spring, whereas the observations show the opposite. In the model, this is due to the asymmetry in the seasonal variations in temperature and, to a lesser extent, $\mathrm{H}_{2} \mathrm{O}$. The temperature asymmetry is in the underlying neutral atmosphere model, and both temperature and $\mathrm{H}_{2} \mathrm{O}$ vary rapidly during the weeks either side of the equinoxes. The variation in peak absorption values is of the order of plus or minus $0.1 \mathrm{~dB}$ from the equinox values, so we cannot ex- 
pect a close fit for the spring/autumn asymmetry between our model and the results of Kavanagh et al. (2012) without taking into account the exact neutral atmosphere conditions for the observations included in the statistical averages.

Overall, the agreement between the daily and seasonal variation of CNA in our model, and the statistical averages of observations, is very good. This gives confidence that the average fluxes published in Meredith et al. (2011), which are the input for our model, are representative of conditions during HSS. Any systematic error in energetic electron fluxes (say by a factor of $X$ ) in the energy ranges included in our model would result in a corresponding error (by approximately $X^{0.5}$ ) in CNA. For example, i.e. a factor of 4 increase (decrease) in flux for UQ-HSS conditions would increase (decrease) peak CNA from 0.47 to $0.94(0.23) \mathrm{dB}$, and seems to be ruled out by the closeness of our model results to the observations. It is difficult to put an exact figure on the uncertainty, but the comparison suggests the fluxes in our UQ and LQ-HSS models might be underestimated, but by less than a factor of 4.

However, it should be remembered that the model results and the observations represent average conditions. In practice, EEP is often intermittent and spatially variable, so that at any particular place and time the measured CNA and the ion production rates will sometimes be much higher or much lower than the average values. In particular, it needs to be recognized that the mean-HSS model has higher fluxes (and higher CNA) than the UQ-HSS model, which indicates that there are a small but significant number of extremely strong events at the high-flux end of the distribution, pushing the mean fluxes above the upper quartile. It should also be noted that CNA is relatively insensitive to ionization by lowerenergy electrons, such as auroral electrons, which can produce strong ionization and $\mathrm{NO}$ production at heights above $90 \mathrm{~km}$. The auroral flux in Table 1, for example, increases CNA by less than $0.1 \mathrm{~dB}$. Auroras are even more variable, both in time and space, than HSS-related EEP, so that auroras may be severely under-sampled in median (as opposed to mean) CNA averages such as presented in Kavanagh et al. (2012).

\section{Comparison with NO observations in the Antarctic winter mesosphere}

We would next like to compare our model results with observed increases in NO densities associated with HSS. The amounts of NO produced each day are very small and NO is rapidly destroyed in sunlight. The best time to do this is in polar winter so that a sufficient amount of NO can be accumulated to give a possibility of detection. It is also better to look in the Southern Hemisphere, where wind systems are more zonally symmetric than in the north, so that mixing between different geographic latitudes is minimized and NO produced poleward of the polar circle can remain in dark- ness for several weeks. One possibility is to use the average winter NO profiles in Fig. 2, subtracting the pre-onset profile from the later profiles to give a measure of the increase. However, due to the fortunate synchronization of Odin observations with a number of unusually well separated HSS arrivals during the austral winter of 2010 , it is also possible to consider a number of discrete events. These are shown in Fig. 5, which covers the period 1 April to 1 September 2010. There are recurrent HSS arrivals, with the main peaks at about the solar rotation period of 27 days, and only minor peaks from secondary coronal holes in between, with a clear correlation to strong increases in NO observed by Odin. Odin made mesospheric measurements on a number of days with different intervals between the observation days $-2,4$, 10 or 14 days - and as a result caught conditions just before, on the day of the onset or the day after, and about 10 days after the onset for several of these HSS. Since we want to be as close as possible to midwinter, and we need to avoid the complication of additional ionization by solar protons, be study only those events corresponding to the peaks in NO densities observed by Odin on 4 May, 1 and 29 June, and 27 July. The timing of the HSS arrivals, defined as the time when the solar wind speed increased through $500 \mathrm{~m} \mathrm{~s}^{-1}$, and the related Odin-SMR observations are summarized in Table 2. In Fig. 5, onset/post-onset days used here are marked by open diamonds, pre-onset days by open circles and observations 10 days after onset by asterisks (observations on 15 June and 6 August are affected by solar protons, so they are not used here).

The solar wind speeds reached in our selected events, 600 $700 \mathrm{~km} \mathrm{~s}^{-1}$, correspond to speeds between the mean and upper quartile in the study of Meredith et al. (2011). The imaging riometer at Maitri (Behera et al., 2012) registered longlasting absorption events on the days following the HSS arrivals - these are summarized in Table 2 in terms of average CNA between 07:00 and 11:00 MLT, which is the time of day when CNA is expected to be most sensitive to the HSSrelated EEP. The measured values in Table 2 can be compared with our models - for winter, the mean, UQ and LQHSS models give averages of $0.83,0.45$ and $0.04 \mathrm{~dB}$ CNA, respectively, for the 07:00-11:00 MLT time interval. The observed values are close to the UQ-HSS model for the last three events, but they are much higher for the first event, almost twice the level of the mean-HSS model, so the fluxes must have been about 4 times higher than the mean-HSS model. Thus it is reasonable to compare the observed increases in NO density for the last three events with our UQHSS model, but we might expect about 4 times more NO production than the mean-HSS model for the first event.

Figure 6 further illustrates the NO changes associated with the HSS, this time showing NO as a function of (geomagnetic) latitude. Each point plotted represents an average of about 40 separate measurements made on the same day at different longitudes and latitudes within a geomagnetic latitude interval. During disturbed conditions the variability from 
Table 2. Time of HSS arrival, dates of available Odin-SMR measurements of NO profiles, and mean CNA measured between 07:00 and 11:00 UT (approx. 08:00-12:00 LT, 06:00-10:00 MLT) by the 38.2 MHz riometer at Maitri, on the 2 days following the HSS arrival, during austral winter 2010 .

\begin{tabular}{|c|c|c|c|c|c|}
\hline HSS arrival & $\begin{array}{l}\text { Odin-SMR } \\
\text { pre-onset }\end{array}$ & $\begin{array}{l}\text { Odin-SMR } \\
\text { onset }\end{array}$ & $\begin{array}{l}\text { Odin-SMR } \\
\text { post onset }\end{array}$ & $\begin{array}{l}\text { Odin-SMR } \\
+10 \text { days }\end{array}$ & $\begin{array}{l}\text { CNA dB } \\
\text { Maitri } \\
\text { arrival }+1 \text {, } \\
+2 \text { days }\end{array}$ \\
\hline 2 May, 15:00 UT & 30 April & - & 4 May & 12, 14 May & $1.5,0.4$ \\
\hline 31 May, 12:00 UT & 28 May & - & 1 June & 11 June & $0.5,0.2$ \\
\hline 29 June, 21:00 UT & 25 June & 29 June & - & 9 July & $0.4,0.2$ \\
\hline 27 July, 09:00 UT & 23 July & 27 July & - & - & $0.3,0.3$ \\
\hline
\end{tabular}

place to place at high latitudes can be expected to increase, increasing the standard error of the mean. These uncertainties are shown by the width of the lines on the plot (the colour fills the values between the mean and plus/minus the standard error of the mean at each point). The uncertainties (line widths) are indeed generally higher at latitudes above $50^{\circ}$ and are highest above $50^{\circ}$ in the Southern Hemisphere during the "POST-ONSET" phase, when they in some cases reach $1 \times 10^{14} \mathrm{~m}^{-3}$. At other latitudes and times they are less than half this amount. Inspection of Fig. 6 shows a strong increase at high latitudes above $85 \mathrm{~km}$ height, by much more than the uncertainties, on the onset/post-onset days, which are within $0-2$ days of the HSS arrival. The increase is most prominent in the Southern (winter) Hemisphere, where it is also not confined to the geomagnetic latitudes where EEP is expected $\left(55-70^{\circ}\right)$ but appears also at higher latitude. Below $85 \mathrm{~km}$, onset and post-onset $\mathrm{NO}$ densities are not significantly above pre-onset levels, when uncertainties are taken into account. By 10 days after the HSS arrival, there is no detectable NO enhancement at northern high latitudes at any height, and at high southern latitudes, NO densities above $95 \mathrm{~km}$ are also close to pre-onset values. However, below $95 \mathrm{~km}$ there are persistent enhancements in the Southern Hemisphere, with a clear increase relative to pre-HSS conditions, at both 75-85 and $85-95 \mathrm{~km}$, as well as a possible increase for some of the events at $65-75 \mathrm{~km}$.

The NO enhancements are further illustrated in Fig. 7, which shows height profiles of the increases in NO corresponding to the HSS events (onset, post-onset and "+ 10 day" profiles with pre-onset profiles subtracted). Here onset and post-onset profiles are shown for the geomagnetic latitude band $60-65^{\circ} \mathrm{S}$ (corresponding to the riometer at Maitri and the latitude of out model calculations), together with profiles of the mean NO increase on onset and post-onset days from all available Odin Southern Hemisphere wintertime observations between May 2007 and September 2014 (with error bars plotted each $7 \mathrm{~km}$ of height, offset in height on the different profiles for clarity). For " +10 days", profiles are included for three latitude bands: $60-65,70-75$ and $80-85^{\circ} \mathrm{S}$.

Our models of ionization rates due to HSS-associated energetic particle precipitation can be used to estimate NO pro- duction rates. Here we use a factor value of 1.25 (Nieder et al., 2014) to convert ionization rate to NO production rate and integrate over $24 \mathrm{~h}$ to give the estimates shown for the HSS "onset" day and $48 \mathrm{~h}$ for the "post-onset" comparison. As discussed in Sect. 2, these can be considered upper-limit estimates for the NO production by the modelled ionization rates. The accumulated production amounts are shown by the black lines in Fig. 7, where we also show the effect of adding auroral precipitation for $4 \mathrm{~h}$ each day. Given the timing of the HSS arrival, and the necessity of averaging over $24 \mathrm{~h}$ to derive the corresponding geomagnetic-zonalmean NO observations, the model-accumulated production amounts should be overestimates rather than underestimates. Further, we have not accounted for losses. Even in the absence of sunlight (i.e. polar winter) there will be NO losses by the reaction $\mathrm{N}+\mathrm{NO}->\mathrm{N}_{2}+\mathrm{O}$ for example as $\mathrm{N}$ is produced by energetic particle ionization. The reaction rate depends on the ionization rate and on the partitioning of $\mathrm{N}$ between excited and ground states (Sinnhuber et al., 2012). For ionization rates below $10^{8} \mathrm{~m}^{-3} \mathrm{~s}^{-1}$, typical for our HSS models, we can expect the NO lifetime to be around 10 days. For ionization rates which are higher by an order of magnitude or more, such as associated with the auroral precipitation, we can expect the NO lifetime to be of the order of a day, possibly much less (Sinnhuber et al., 2012). Comparing the accumulated NO amounts from our models with the observations for onset and post-onset in Fig. 7, it is clear that much more NO has appeared above $85-90 \mathrm{~km}$ altitude than the (overestimated) LQ, UQ and mean-HSS model predictions - by factors of up to 3 in the case of the Odin mean profile and factors of up to 10 for the individual HSS events during winter 2010. Although there were indications that the first of the events (2 May) could have led to about 4 times more NO production than the mean-HSS model, there is no reason to believe that the other events are above that model level. However it is also clear that the addition of the auroral source can produce very large amounts of NO above $100 \mathrm{~km}$ height, even though we have assumed that it acts for only 4 out of each $24 \mathrm{~h}$. Most likely, the large increases in NO above $85-90 \mathrm{~km}$ altitude are due to auroral electron precipitation. 

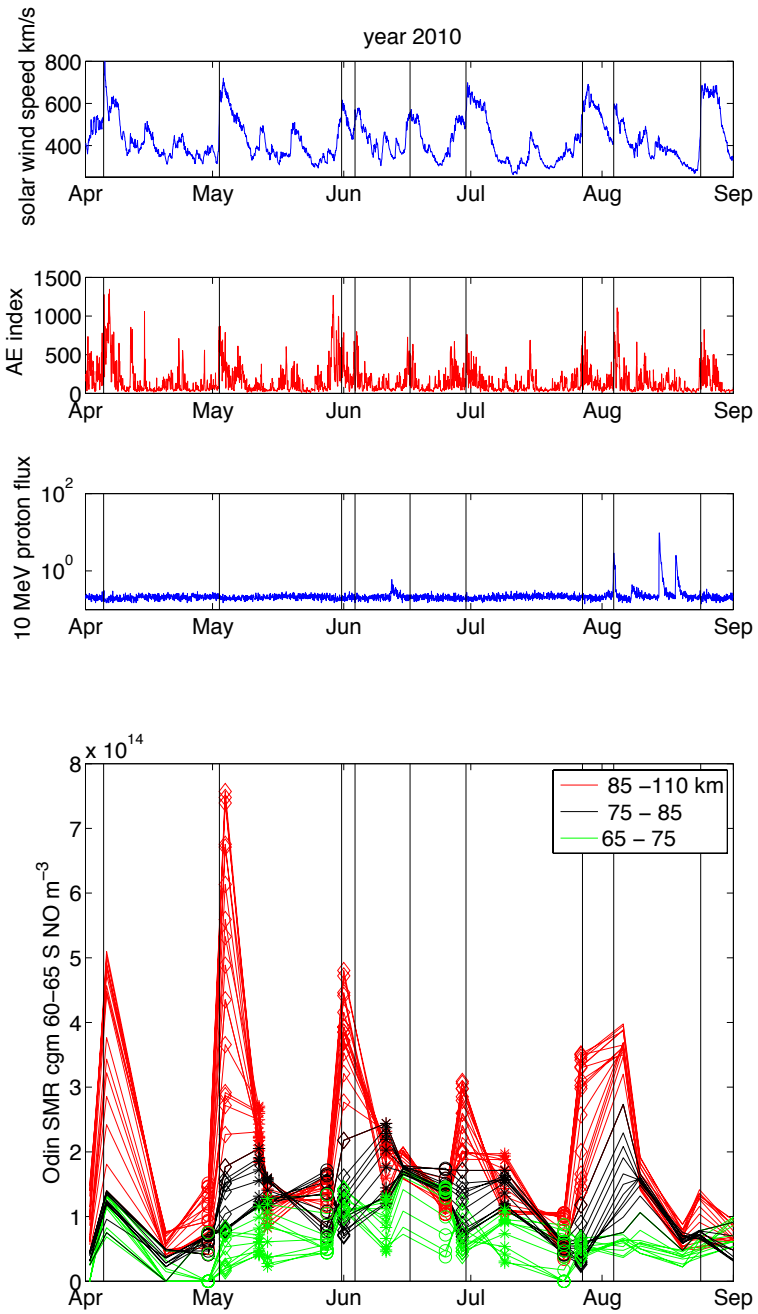

Figure 5. Observations of $24 \mathrm{~h}$ averaged NO number densities in the $60-65^{\circ} \mathrm{S}$ geomagnetic latitude band by the Odin-SMR instrument (bottom panel) associated with the arrival of high-speed solar wind streams (top panel) during austral winter in 2010. Middle panels show the auroral electrojet index and the flux of $10 \mathrm{MeV}$ protons (from http://omniweb.gsfc.nasa.gov/). Vertical lines mark the times of arrival of high-speed solar wind streams ("onset"). Observations used in Figs. 6 and 7 are marked by open circles (preonset), diamonds (onset or immediately post-onset) and asterisks (about 10 days after onset).

Below $85 \mathrm{~km}$ there is no systematic increase in NO for the individual events for onset/post-onset days, but the Odin mean profiles show small increases which are similar to our HSS-mean model. Given the large variability in the individual events, and the very low modelled NO production rates compared to standard errors in the observed mean enhancements (error bars in the left-hand and centre panels of Fig. 7), we can only say that direct NO is able to contribute a significant proportion of mean (over several events) enhancement in NO at $70-85 \mathrm{~km}$ in the first 2 days after HSS arrival, but the amount is too low to be detected for individual events.
When we consider the situation about 10 days after the arrival of the HSS, we must consider that the EEP fluxes reduce with time and also take into account spreading of $\mathrm{NO}$ produced in the geomagnetic zone $55-70^{\circ} \mathrm{S}$ to other geomagnetic latitudes. There is a large offset (about $15^{\circ}$ ) between the geographic and geomagnetic poles in the Southern Hemisphere, so that geographically zonal winds can spread $\mathrm{NO}$ over all geomagnetic latitudes poleward of $40^{\circ} \mathrm{S}$. For the model estimates of accumulated $\mathrm{NO}$ production in the righthand panel of Fig. 7, we have assumed that EEP fluxes remain the same for the first 3 days, and then reduce by $10 \%$ per day until the 10th day, an approximation to the statistical results in Meredith et al. (2011). We make an assumption that production is the same as our models over the whole geomagnetic zone $55-70^{\circ} \mathrm{S}$ and that this is redistributed over the whole region poleward of $45^{\circ} \mathrm{S}$ geographic latitude. Comparing the areas of the two zones, gives a factor of 0.52 reduction in average accumulated NO concentration when it is diluted by spreading over the larger zone. In the observations (right-hand panel of Fig. 7 and lowest panel of Fig. 6), it is clear that the large amounts of NO above $90 \mathrm{~km}$ are no longer present after 10 days, but NO has increased substantially between 70 and $90 \mathrm{~km}$, at all latitudes poleward of $60^{\circ} \mathrm{S}$, with the highest increase at the highest geomagnetic latitudes. In the right-hand panel of Fig. 7, it can be seen that the observed amounts of NO are highly variable but, on average, close to our mean-HSS models of accumulated direct production (corrected for spatial spread). From the CNA observed at Maitri, it seems that EEP fluxes might have been as high as 4 times our mean-HSS model on one occasion (HSS arrival on 2 May), at least at the location of Maitri. If this applied to the whole precipitation region, the accumulated NO production should be 4 times higher, but the observed NO enhancements (solid red lines) are not larger than for the other events. We have not accounted for losses in our model estimates. The lifetime of NO at these heights in polar winter, with the HSS-related ionization rates, is expected to be of the order of 10 days (Sinnhuber et al., 2012), so about half would have been lost by recombination with $\mathrm{N}$. It should also be remembered that our NO production rate estimates are upper limits. Therefore the observed enhancements likely exceed direct production by a factor which could be up to 4 . However there also is a possible high bias in OdinSMR NO estimates by up to $40 \%$ (Sheese et al., 2013; Bender et al., 2014). In summary, according to our approximate calculations, it seems unlikely that enough $\mathrm{NO}$ was produced directly at $70-90 \mathrm{~km}$ altitude to explain the observed NO increases by direct production and horizontal transport alone. It is likely that downward transport contributed, but, since the direct production is of the same order as the total observed enhancement, and the uncertainties in both model and observations are also of similar magnitude, we cannot say this for sure. 

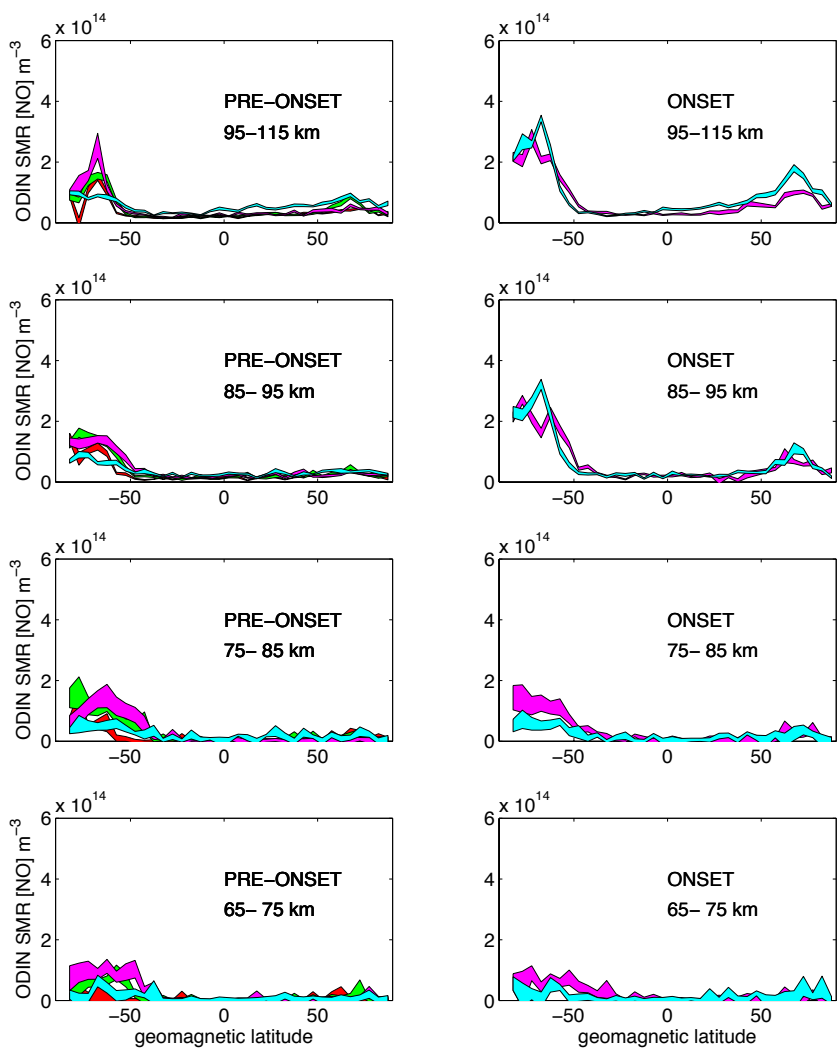
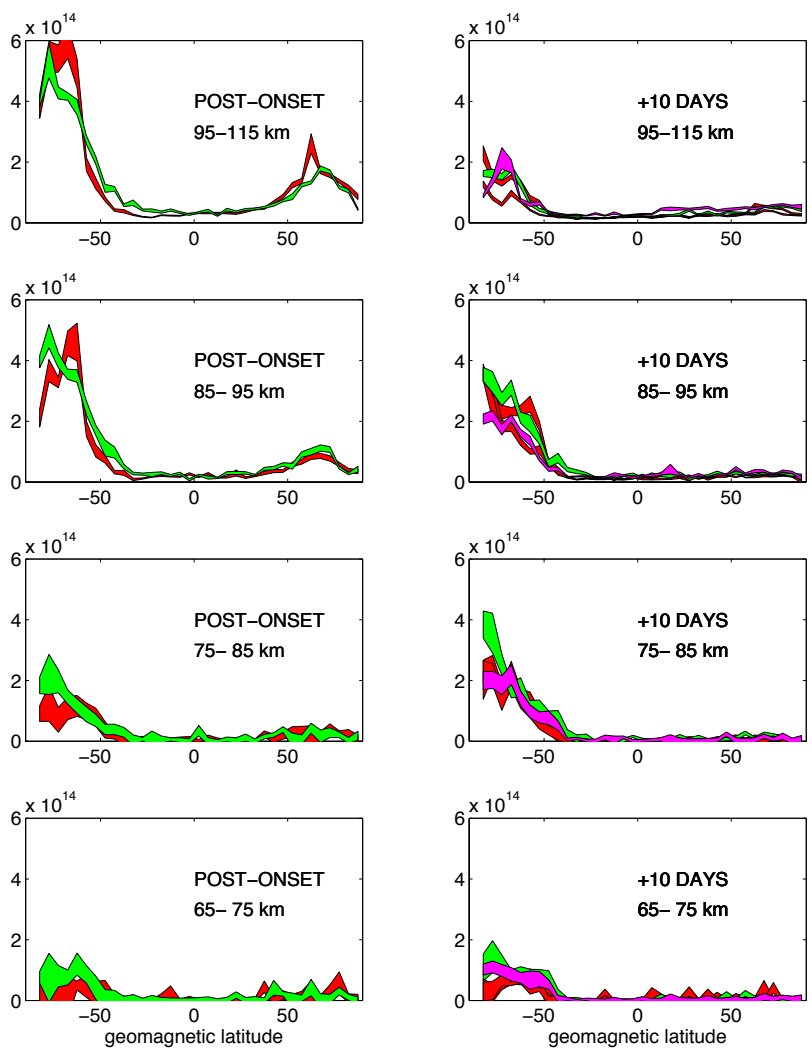

Figure 6. Observations of NO number densities by the Odin-SMR instrument before, during and after the arrival of high-speed solar wind streams during austral winter in 2010, plotted as a function of geomagnetic latitude. Broad, colour-filled lines show values between zonal mean and plus and minus the standard error of the mean. Colours indicate the different events in Table 2: red, 2 May; green, 31 May; magenta, 29 June; cyan, 27 July.
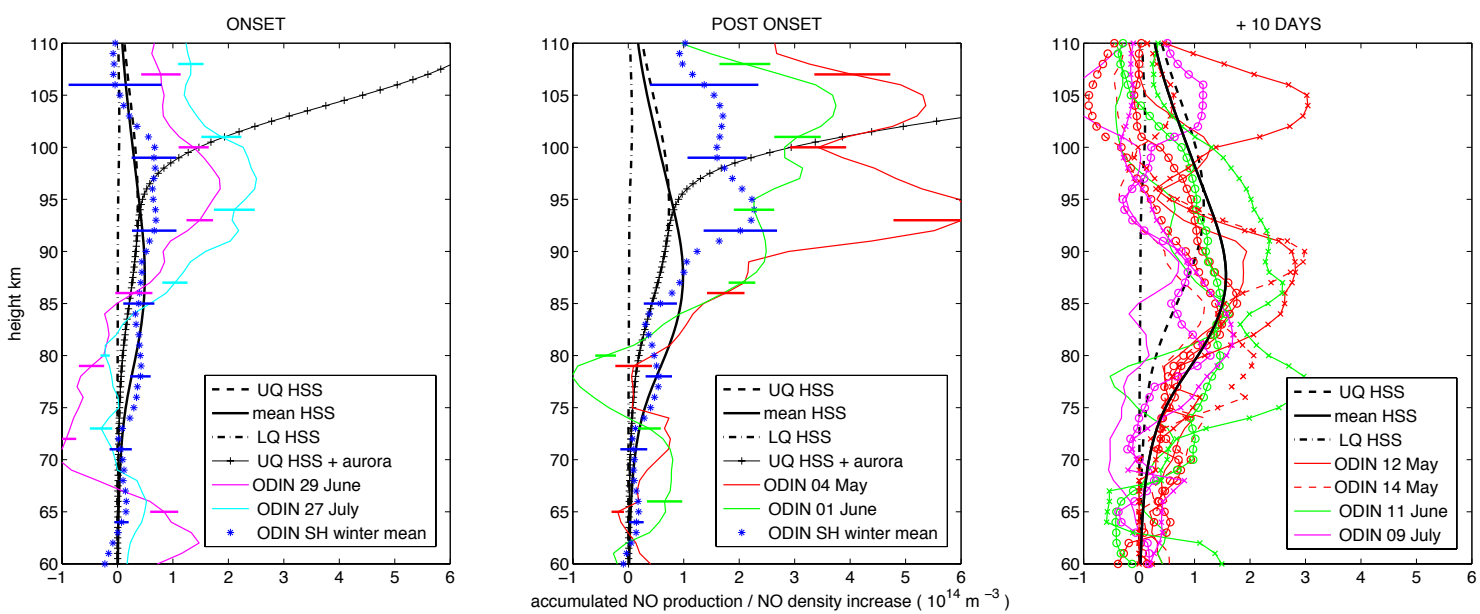

Figure 7. Comparison of modelled NO production with Odin-SMR observations of NO number density increase during HSS. Model profiles, corresponding to the different models of incoming energetic electron fluxes listed in Table 1, are shown in black for NO total production during 1 day (left-hand panel labelled "ONSET"), 2 days (middle panel labelled "POST-ONSET"), and 10 days (with steadily decreasing flux, right-hand panel labelled "+ 10 DAYS"). "Aurora" fluxes are applied for only $4 \mathrm{~h}$ each day, and HSS fluxes for the whole day. Observations are the differences between pre-onset, onset and post-onset observations for four HSS events shown in Fig. 6 (solid lines) and for the average of all Southern Hemisphere wintertime HSS events covered by Odin-SMR measurements during the years 2007-2014 (*). All observations are based on zonal averages over UT days and $5^{\circ}$ bands of geomagnetic latitude. Left and centre panels for geomagnetic latitude $60-65^{\circ} \mathrm{S}$, and right panel for geomagnetic latitudes $60-65^{\circ} \mathrm{S}$ (no marks along line), $70-75^{\circ} \mathrm{S}$ (circles) and $80-85^{\circ} \mathrm{S}$ (crosses) 


\section{Conclusions}

The first result of this study is that there is excellent quantitative consistency between the statistical characteristics of EEP fluxes determined from the POES satellites (Meredith et al., 2011) and the average response in the ionospheric D region as measured by CNA (Kavanagh et al., 2012). This means there is no evidence, at least as far as average HSS-conditions are concerned, to support the suggestion by Rodger et al. (2013) that POES underestimates EEP fluxes by several orders of magnitude. This gives confidence that the HSS-associated EEP fluxes from Meredith et al. (2011) can be used for quantitative estimates of the contribution of HSS to NO production in the D-region.

The second result is that seasonal variations in the HSSrelated CNA response, observed by Kavanagh et al. (2012), can be quantitatively reproduced by seasonal changes in ion chemistry, without any seasonal changes in EEP. This confirms the suggestion by Kavanagh et al. (2012) that mesospheric chemistry might provide an explanation.

The third result is that the ion-chemistry model shows that CNA is most sensitive to EEP during daytime, and least sensitive during night, when negative ions form. This means that lower-energy (auroral) precipitation can make a significant contribution to CNA at night, since ion chemistry affecting the lower part of the $\mathrm{D}$ region reduces the contribution of more energetic electrons to the electron-density profile. This may explain the results of Rodger et al. (2013), who found substantial discrepancies between POES measurements of EEP and simultaneous/co-located CNA, as the latter study used night-time observations in the auroral zone.

The fourth result concerns the production of NO by HSSrelated EEP. For a series of HSS events in austral winter 2010, we have shown that observations of NO enhancements in the mesosphere over Antarctica (by the Odin satellite) show significant enhancements after 10 days at heights 70 $95 \mathrm{~km}$. The enhancements are of the same order of magnitude but possibly larger than those expected from direct production by EEP. The largest amounts of NO are produced by lower-energy (auroral) electrons above $90 \mathrm{~km}$ altitude, and downward transport of this NO likely also contributes.

Finally, we can make a quantitative comparison with the amount of HSS-related NO production implied by the EEP fluxes in Meredith et al. (2011) and the amounts found in the study by Rozanov et al. (2005), which were suggested to have a significant climate effect. Column production rates of $\mathrm{NO}_{y}$ (calculated as 1.2 times the ion production rate), summed over $60-90 \mathrm{~km}$ altitude and averaged over $24 \mathrm{~h}$ after HSSonset, are $6 \times 10^{17} \mathrm{~m}^{-2} \mathrm{day}^{-1}$ for our mean-HSS model and $3 \times 10^{17} \mathrm{~m}^{-2} \mathrm{day}^{-1}$ for UQ-HSS. In the study by Rozanov et al. (2005), intermittent peaks in $\mathrm{NO}_{y}$ production rates were estimated to be in the range of $3-16 \times 10^{18} \mathrm{~m}^{-2} \mathrm{day}^{-1}$. This is an order of magnitude more than the HSS-related production according to our present study.
Acknowledgements. This research has been partly funded by the Swedish Research Council (grant 621-2010-3218). Summary plots of Maitri riometer data were supplied by Lancaster University, England. Odin is a Swedish-led satellite project funded jointly by the Swedish National Space Board (SNSB), the Canadian Space Agency (CSA), the National Technology Agency of Finland (Tekes), the Centre National d'Etudes Spatiales (CNES) in France and through the Third Party Missions programme of the European Space Agency (ESA).

The topical editor C. Jacobi thanks M. Friedrich and the two anonymous referees for help in evaluating this paper.

\section{References}

Baker, D. and Li, X.: Relativistic Electron Flux Enhancements During Strong Geomagnetic Activity, in: Disturbances in Geospace: The Storm-Substorm Relationship, edited by: Sharma, A. S., Kamide, Y., and Lakhina, G. S., AGU Washington, 217 pp., doi:10.1029/142GM18, 2003.

Barabash, V., Osepian, A., Dalin, P., and Kirkwood, S.: Electron density profiles in the quiet lower ionosphere based on the results of modeling and experimental data, Ann. Geophys., 30, 13451360, doi:10.5194/angeo-30-1345-2012, 2012.

Barabash, V., Osepian, A., and Dalin, P.: Influence of water vapour on the height distribution of positive ions, effective recombination coefficient and ionisation balance in the quiet lower ionosphere, Ann. Geophys., 32, 207-222, doi:10.5194/angeo-32207-2014, 2014.

Behera, J. K., Sinha, A. K., Singh, A. K., Rawat, R., Vichare, G., Dhar, A., Pathan, B. M., Nair, K. U., Selvaraj, C., and Elango, P.: First results from imaging riometer installed at Indian Antarctic station Maitri, J. Earth Syst. Sci., 123, 593-602, 2012.

Bender, S., Sinnhuber, M., von Clarmann, T., Stiller, G., Funke, B., López-Puertas, M., Urban, J., Pérot, K., Walker, K. A., and Burrows, J. P.: Comparison of nitric oxide measurements in the mesosphere and lower thermosphere from ACE-FTS, MIPAS, SCIAMACHY, and SMR, Atmos. Meas. Tech. Discuss., 7, 12735-12794, doi:10.5194/amtd-7-12735-2014, 2014.

Dickinson, P. H. G. and Benett, F. D. G.: Diurnal variations in the D-region during a storm after-effect., J. Atmos. Terr. Phys., 40, 549-558, 1978.

Hartogh, P., Sonnemann, G. R., Grygalashvily, M., Li Song, Berger, U., and Lübken, F. J.: Water vapour measurements at ALOMAR over a solar cycle compared with model calculations by LIMA, J. Geophys. Res., 115, D00117, doi:10.1029/2009JD012364, 2010.

Hedin, A. E.: Extension of the MSIS thermosphere model into the middle and lower atmosphere, J. Geophys. Res., 96, 1159-1172, 1991.

Jackman, C. H., Randall, C. E., Harvey, V. L., Wang, S., Fleming, E. L., López-Puertas, M., Funke, B., and Bernath, P. F.: Middle atmospheric changes caused by the January and March 2012 solar proton events, Atmos. Chem. Phys., 14, 1025-1038, doi:10.5194/acp-14-1025-2014, 2014.

Kashirin, A. I.: Photoionization of the nightime ionosphere, Geomagn. Aeron., 26, 563-568, 1986.

Kavanagh, A. J., Honary, F., Donovan, E. F., Ulich, T., and Denton, M. H.: Key features of $>30 \mathrm{keV}$ electron precipitation during 
high speed solar wind streams: A superposed epoch analysis, J. Geophys. Res., 117, A00L09, doi:10.1029/2011JA017320, 2012.

Kirkwood, S. and Eliasson, L.: Energetic particle precipitation in the substorm growth phase measured by EISCAT and Viking, J. Geophys. Res., 95, 6025-6037, 1990.

Kirkwood, S. and Osepian, A.: Quantitative studies of energetic particle precipitation using incoherent-scatter radar, J. Geomag. Geoelec., 47, 783-799, 1995.

Kirkwood, S., Osepian, A., and Smirnova, N.: Quantitative description of electron precipitation during auroral absorption events in the morning/noon local-time sector, J. Atmos. Sol. Terr. Phys., 63, 1907-1921, 2001.

Kirkwood, S., Barabash, V., Belova, E., Nilsson, H., Rao, T. N., Stebel, K., Osepian, A., and Chilson, P. B.: Polar mesosphere winter echoes during solar proton events, Adv. Polar Upper Atmos. Res., 16, 111-125, 2002.

Kirkwood, S., Belova, E., Dalin, P., Mihalikova, M., Mikhaylova, D., Murtagh, D., Nilsson, H., Satheesan, K., Urban, J., and Wolf, I.: Response of polar mesosphere summer echoes to geomagnetic disturbances in the Southern and Northern Hemispheres: the importance of nitric oxide, Ann. Geophys., 31, 333-347, doi:10.5194/angeo-31-333-2013, 2013.

Lyons, L. R., Thorne, R. M., and Kennel, C. F.: Pitchangle diffusion of radiation belt electrons within the plasmasphere, J. Geophys. Res.-Space, 77, 3455-3474, doi:10.1029/JA077i019p03455, 1972.

McKinnel, L.-A. and Friedrich, M.: A neural-network based ionospheric model for the auroral zone., J. Atmos. Sol. Terr. Phys., 69, 1459-1470, 2007.

Meredith, N. P., Horne, R. B., Lam, M. M., Denton, M. H., Borovsky, J. E., and Green, J. C.: Energetic electron precipitation during high-speed solar wind stream driven storms., J. Geophys. Res., 116, A05223, doi:10.1029/2010JA016293, 2011.

Murtagh, D., Frisk, U., Merino, F., Ridal, M., Jonsson, A., Stegman, J., Witt, G., Eriksson, P., Jiménez, C., Mégie, G., de La Noë, J., Ricaud, P., Baron, P., Pardo, J., Hauchecorne, A., Llewellyn, E., Degenstein, D., Gattinger, R., Lloyd, N., Evans, W., McDade, I., Haley, C., Sioris, C., von Savigny, C., Solheim, B., McConnell, J., Strong, K., Richardson, E., Leppelmeier, G., Kyrölä, E., Auvinen, H., and Oikarinen, L.: An overview of the Odin atmospheric mission, Can. J. Phys., 80, 309-319, 2002.

Nieder, H., Winkler, H., Marsh, D. R., and Sinnhuber, M.: NO $x$ production due to energetic particle precipitation in the MLT region : Results from ion-chemistry model studies, J. Geophys. Res., 119, 2137-2148, doi:10.1002/2013JA019044, 2014.

Osepian, A., Tereschenko, V., Dalin, P., and Kirkwood, S.: The role of atomic oxygen concentration in the ionization balance of the lower ionosphere during solar proton events, Ann. Geophys., 26, 131-143, doi:10.5194/angeo-26-131-2008, 2008.

Osepian, A., Kirkwood, S., and Dalin, P.: The influence of ozone concentration on the lower ionosphere - modelling and measurements during the 29-30 October 2003 solar proton event, Ann. Geophys., 27, 577-589, doi:10.5194/angeo-27-577-2009, 2009a.

Osepian, A., Kirkwood, S., Dalin, P., and Tereschenko, V.: D-region electron density and effective recombination coefficients during twilight - experimental data and modelling during solar proton events, Ann. Geophys., 27, 3713-3724, doi:10.5194/angeo-273713-2009, 2009b.
Rees, M. H.: Auroral ionisation and excitation by incident energetic electrons, Planet. Space Sci., 11, 1209-1218, 1963.

Rodger, C. J., Kavanagh, A. J., Clilverd, M. A., and Marple, S. R.: Comparison between POES energetic electron precipitation observations and riometer absorptions: Implications for determining true precipitation fluxes, J. Geophys. Res. Space Physics, 118, 7810-7821, doi:10.1002/2013JA019439, 2013.

Rong, P. P., III, J. M. R., Gordley, L. L., Hervig, M. E., Deaver, L., Bernath, P. F., and Walker, K. A.: Validation of v1.022 mesospheric water vapor observed by the Solar Occultation for Ice Experiment instrument on the Aeronomy of Ice in the Mesosphere satellite, J. Geophys. Res., 115, D24314, doi:10.1029/2010JD014269, 2010.

Rozanov, E., Callis, L., Schlesinger, M., Yang, F., Andronova, N., and Zubov, V.: Atmospheric response to NOy source due to energetic electron precipitation, Geophys. Res. Lett., 32, L14811, doi:10.1029/2005GL023041, 2005.

Sergienko, T. I. and Ivanov, V. E.: A new approach to calculate the excitation of atmospheric gases by auroral electron impact, Ann. Geophys., 11, 717-727, 1993, http://www.ann-geophys.net/11/717/1993/.

Sheese, P. E., Strong, K., Gattinger, R. L., Llewellyn, E. J., Urban, J., Boone, C. D., and Smith, A. K.: Odin observations of Antarctic nighttime NO densities in the mesosphere-lower thermosphere and observations of a lower NO layer, J. Geophys Res., 118, 7414-7425, doi:10.1002/jgrd.50563, 2013.

Sinnhuber, M., Nieder, H., and Wieters, N.: Energetic particle precipitation and the chemistry of the mesosphere/lower thermosphere, Surv. Geophys., 33, 1281-1334, doi:101007/s10712012-9201-3, 2012.

Sinnhuber, M., Funke, B., von Clarmann, T., Lopez-Puertas, M., Stiller, G. P., and Seppälä, A.: Variability of $\mathrm{NO}_{x}$ in the polar middle atmosphere from October 2003 to March 2004: vertical transport vs. local production by energetic particles, Atmos. Chem. Phys., 14, 7681-7692, doi:10.5194/acp-14-76812014, 2014.

Smirnova, N., Ogloblina, O., and Vlaskov, V.: Modelling of the lower ionosphere, Pageophys., 127, 353-379, 1988.

Torkar, K. M. and Friedrich, M.: Tests of an ion-chemical model in the D and lower E region, J. Atmos. Terr. Phys., 35, 369-385, 1983.

Torkar, K. M., Friedrich, M., and Stauning, P.: Evidence of coupling between auroral zone activity and mid-latitude absorption., J. Atmos. Terr. Phys., 42, 183-188, 1980.

Urban, J., Lautie, N., Murtagh, D., Eriksson, P., Kasai, Y., Loßow, S., Dupuy, E., de La Noe, J., Frisk, U., Olberg, M., Le Flochmoën, E., and Ricaud, P.: Global observations of middle atmospheric water vapour by the Odin satellite: An overview., Planet. Space Sci., 55, 1093-1102, doi:10.1016/j.pss.2006.11.021, 2007.

Verronen, P. T., Turunen, E., Ulich, Th., and Kyrölä, E.: Modelling the effects of the October 1989 solar proton event on mesospheric odd nitrogen using a detailed ion and neutral chemistry model, Ann. Geophys., 20, 1967-1976, doi:10.5194/angeo-201967-2002, 2002. 